\title{
DESIGN OF AN ELEVATOR PROTOTYPE PROPELLED BY A LINEAR INDUCTION MOTOR
}

\author{
T. R. Fernandes Neto, R. S. T. Pontes \\ University of Ceará- Electrical Engineering Department \\ Campus do Pici, P.O.Box 6001, ZIP code: 60.455-760, Fortaleza ,CE - Brazil \\ tobias@dee.ufc.br, ricthe@dee.ufc.br
}

\begin{abstract}
This work aims at the design of a roped elevator prototype, which uses a linear induction motor (LIM) as a traction machine. It is also concerned with the development of a specific inverter to feed the linear motor that allows several ways to drive the elevator through a suitable choice of the RMS voltage levels, angular phase displacement and electrical frequency of the output voltage. The result tries to establish a new concept for elevators through a new construction technique and assembly of the system with counterweight, which increases the reliability and comfort with cost reduction.
\end{abstract}

Keywords - drives, elevators, linear induction motor, power electronics.

\section{INTRODUCTION}

Nowadays, the vast majority of applications, in those a linear motion is necessary, use a rotary electrical motor as source of motion in order to convert the rotary motion into a linear motion. Often, it is necessary to use a complex mechanical system of gears, axles and screws jacks. When used directly, these transmission systems for movement have great losses. Among the reasons for these losses, there is the increased abrasive wear due to the friction of the mechanical parts, even when using low viscosity fluids for the lubrication. This results into higher operational and maintenance costs [1]. Therefore, for transport applications, the use of an electrical machine that produces directly the linear motion would result in lower operational and maintenance costs as well as higher reliability and efficiency $[1,2]$.

This work intends to build an elevator prototype system using a linear induction motor, fed by a suitable converter, which takes into consideration the desired drive.

\section{LINEAR MOTORS}

The linear motor design can be obtained by geometrically arranging of a rotary motor into a linear configuration; along the radius of the rotary motor, from the center of the shaft to the external surface of the stator core. The motor is rolled out flat, as it is schematically shown in Figure 1. Therefore, for each type of rotary electrical machine (synchronous, inductance, reluctance and direct current), there is a linear equivalent.

Manuscript received on 31/08/2008. Revised on 23/03/2009 and 29/06/2009. Accepted by recommendation of the Editor Fernando L. M. Antunes.
Linear motors were first developed at the end of eighteen century at the same time as the other rotary electrical machines [1].

Difficulties in driving the linear motor due to its operation characteristics as well as the problems caused by the

longitudinal end and transverse edge effects, characteristic from linear machines, restricted its use to a few applications [1]. Besides, AC motor drives had initially fixed supply voltage and frequency and the required increased complexity in linear motor drives was not available, which also limited the use of linear machines. This resulted in turning the linear machines simply into a theoretical reference for almost the entire first half of the $\mathrm{XX}$ century [2].

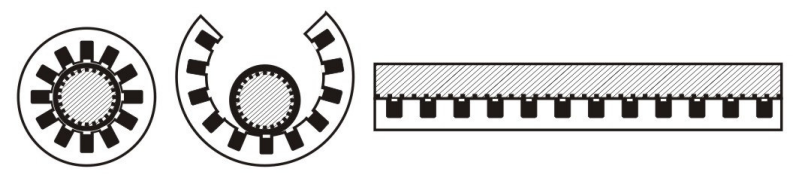

Fig. 1. Imaginary building process of a linear induction motor (LIM).

The development of power electronics associated with the microprocessor allowed speed control, adjustment of the thrust and breaking control improving efficiency and security. Thus, some applications are becoming advantageous when compared with the equivalents driven by rotary electrical machines [2, 3].

The perspectives of future applications of the linear machines in the industry are each time more promising, such as: pallet transportation, belt conveyors transportation of bulk material, machine tools, presses mills, separators, automated manufacturing systems, strip tensioners, textile shuttles, turntables, disc saws, military and aerospace applications, hypervelocity, ship propulsion and submarines, biomedical applications, elevators, load transport.

\section{LINEAR MOTORS IN ELEVATORS}

The linear motor has been studied for the vertical conveying application because its main characteristic is the linear motion, which takes place without transformation mechanisms, increasing the efficiency and the reliability of the system and also eliminating the need for a bulky machine room on the roof [4].

Since the beginning of the research for the use of the linear motor in vertical drives, the type of the electrical machine (i.e. synchronous, induction and reluctance) or the configuration to be used (i.e. single or double sided and tubular) became a great source of discussion among the researchers $[5,6,7,8,9]$. Many authors $[5,7,8,10,11]$ 
extended and improved first approaches about elevators, e.g. the motor does the work of dislocating all the traveling weight (ropeless) or one can use a rope with counterweight (roped) decreasing thrust supplied for the motors, but the experimental work is generally missing. However the best configuration for such application is a problem to be solved. It is already expected that linear motors can generally provide several important advantages when compared with configurations based on rotary motors [4]:

- Performance of the linear motors is comparable to that of rotary motors;

- Smooth operation and high comfort of riding can be obtained;

- Greater adaptability to the environment (building), e.g. penthouse machine room is not required, reduction of overhead space;

- It is possible to use the linear motor as a breake;

- Linear motor acts not only as a driving device but also as part of the counterweight;

- Energy saving and reduction in power capacity are possible.

\section{DESIGN OF A COUNTERWEIGHT ELEVATOR PROTOTYPE USING A LINEAR MOTOR DRIVE}

Several design criteria have been applied to the LIM configuration and are listed as follows.

1) The elevator system will be shuttled by a double sided LIM;

2) The LIM will be used as traction machine and counterweight;

3) The linear motor must have a reduced size, due to the height $(3 \mathrm{~m})$ conditions of the laboratory (GPAR) of the Department of Electric Engineering;

4) This LIM must have a low speed, thus the maximum cruising speed was limited to $1.2 \mathrm{~m} / \mathrm{s}$ for a frequency of 20 $\mathrm{Hz}$;

5) The primary core will have opened rectangular slots;

6) The LIM will carry the weight of the car structure plus the payload, thus the rated force will be of $200 \mathrm{~N}$;

7) The rated voltage will be of 220 volts;

8) The mechanical structure of the elevator prototype will be designed for 3 meters height;

9) The elevator prototype will have along the path two stops (two floors).

With the specified design criteria parameters the motor was designed according to the section $\mathrm{V}$ and then, the mechanical structure of the elevator was built.

After that, the inverter was designed and finally were used a microprocessor (PIC16F877) to control the position of the elevator in each floor and a digital signal processor (TMS320F2812) to control the inverter itself (switching, breaking, acceleration).

\section{DESIGN OF A DOUBLE-SIDED LINEAR INDUCTION MOTOR}

The theoretical design of a LIM begins with the calculation of the main dimensions, i.e. pole pitch, number of slots, slot pitch, slot width, tooth width, length of the primary and width of the primary.
The airgap between the primary and secondary cores is designed to be $1 \mathrm{~mm}$, as shown in Figure 2.

Oriented silicon steel sheets are used to assembly the primary core and to use all the sheet extension $(450 \times 100 \mathrm{~mm})$. Therefore, the primary core has 12 magnetic poles.

The geometry sizes for a LIM are obtained from the design procedure stated below.

The pole pitch is:

$$
\tau=\frac{v_{r}}{(1-s) \cdot 2 \cdot f}
$$

Where:

$$
\begin{array}{ll}
\mathrm{V}_{\mathrm{r}} & \text { - Desired speed. } \\
\tau & \text { - Pole pitch. } \\
\mathrm{f} & \text { - Electrical frequency. }
\end{array}
$$
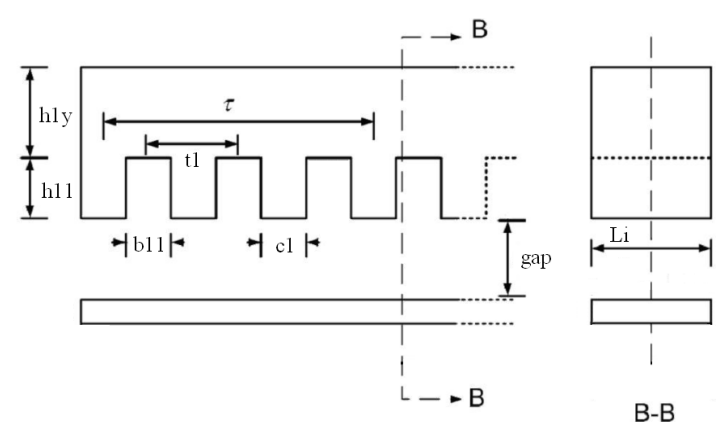

Fig. 2. LIM geometry.

The length of the primary core is given by:

$$
L_{\tau}=\left(2 \cdot p \cdot \tau+w c+c_{1}\right)
$$

Where:

$\mathrm{L}_{\tau} \quad$ - Length of the primary core.

p - Number of pairs of poles.

wc - Coil pitch.

c1 - Tooth width

The yoke height of the primary core is the portion of the core above the teeth, as shown in Figure 2. The flux in the yoke is one-half of the flux in the airgap [12]. The required height of the yoke in order to carry the flux without excessive saturation can be expressed as:

$$
\begin{gathered}
\Phi_{\text {pole }}=2 \cdot \Phi_{\text {yoke }} \\
h 1 y=\tau \cdot \frac{B_{m z}}{2 \cdot B_{m 1 y}}
\end{gathered}
$$

Where:

$\Phi_{\text {pole }}$ - Flux per pole.

$\Phi_{\text {yoke }}$ - Flux in the yoke.

$\mathrm{B}_{\mathrm{mz}}$ - Average air gap flux density for one pole pitch.

$B_{m 1 y}$ - Assumed magnetic flux density in the yoke.

h1y - Height of the yoke of the primary core.

For the type of motors being considered, a thrust of 2000 $\mathrm{N} / \mathrm{m}^{2}$ can be produced without any excessive heating in the primary winding $[12,13]$. Based on the above dimensions the width of the primary core is: 


$$
L i=\frac{F}{L_{\tau} \cdot \xi}
$$

Where:

$\mathrm{L}_{\mathrm{i}} \quad$ - Width of the primary core.

$\xi \quad$ - Desired specific thrust per square meter

The primary slot pitch have width dimension, given by:

$$
t_{1}=\frac{2 \cdot p \cdot \tau}{z}
$$

Where:

t1 - Slot pitch.

z $\quad$ - Number of slots.

To avoid magnetic saturation in the primary teeth, there is a minimum value of tooth width (see Figure 2), which depends on the assumed magnetic flux density in the tooth.

The magnetic flux per pole is three times the magnetic flux per teeth [14]. Hence the tooth width can be calculated with:

$$
\begin{aligned}
& \Phi_{\text {pole }}=3 \cdot \Phi_{\text {tooth }} \\
& c 1=\frac{t 1 \cdot B_{m z}}{B_{m 1 t}}
\end{aligned}
$$

Where:

$\mathrm{B}_{\mathrm{mlt}}$ - Assumed magnetic flux density in the tooth.

The slot pitch is the sum of the slot width and the tooth width and hence the slot width can be calculated with:

$$
b 11=t 1-c 1
$$

The primary core has 39 slots and was determined from:

$$
z=2 p \cdot m \cdot q
$$

Where:

m - Number of phases.

q - Number of slots per poles per phases.

For a three-phase configuration of 12 poles, the LIM was designed with a double-layer distribution in the thirty three central slots and a mono-layer in the six slots at utmost point, concerning three in the entrance slots and three at end of exit slot, as shown in Figure 3.

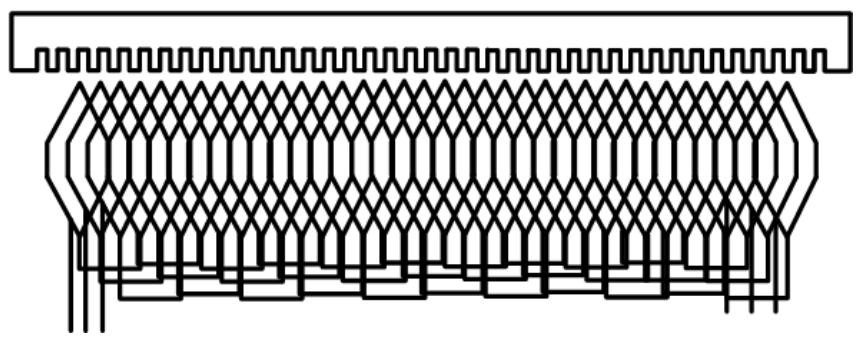

Fig. 3. Winding configuration of the primary core.

This configuration of winding together with length extension of the primary stack tries to reduce the longitudinal end effects [2].

The winding of the primary core has 198 turns per slot using the wire gauge of $\# 22 \mathrm{AWG}\left(0,33 \mathrm{~mm}^{2}\right)$ given by:

$$
N_{1}=\frac{V_{1} \cdot k_{v}}{\sqrt{2} \cdot \pi \cdot f \cdot k_{w 1} \cdot B_{m z} \cdot L i \cdot \tau}
$$

Where:

$\mathrm{N}_{1} \quad$ - Number of turns per phase.

$\mathrm{k}_{\mathrm{v}} \quad$ - Voltage drop factor.

$\mathrm{k}_{\mathrm{w} 1}$ - Winding factor.

$\mathrm{V}_{1} \quad$ - Input phase voltage

Therefore, the number of turns per slot is:

$$
N_{s l}=\frac{N_{1}}{p \cdot q}
$$

Where:

$\mathrm{N}_{\mathrm{s} 1} \quad$-Number of conductors in each slot.

The height of the slot h11 can be determined as follows:

$$
h 11=\frac{N_{1} I_{1}}{p \cdot q \cdot J \cdot k_{\text {fill }}}
$$

Where:

J - Current density in the primary winding.

$\mathrm{k}_{\text {fill }} \quad$ - The slot fill factor.

$\mathrm{I}_{1} \quad$ - Current in the primary winding

The dimensions from the design of the primary core are depicted in Table 1.

TABLE I

Size of the primary core

\begin{tabular}{ccc}
\hline Quantity & LIM & Unit \\
\hline Length of primary core, $\mathrm{L}_{\tau}$ & 450 & $\mathrm{~mm}$ \\
\hline Width of primary core, $\mathrm{L}_{\mathrm{i}}$ & 70 & $\mathrm{~mm}$ \\
\hline Pole pitch, $\tau$ & 30 & $\mathrm{~mm}$ \\
\hline Height of the yoke, $\mathrm{h} 1 \mathrm{y}$ & 30 & $\mathrm{~mm}$ \\
\hline Height of the slot, h11 & 30 & $\mathrm{~mm}$ \\
\hline Height of primary core, (h11+h1y) & 60 & $\mathrm{~mm}$ \\
\hline Tooth width, $\mathrm{c} 1$ & 5 & $\mathrm{~mm}$ \\
\hline Slot width, b11 & 5 & $\mathrm{~mm}$ \\
\hline Slot pitch, $\mathrm{t} 1$ & 10 & $\mathrm{~mm}$ \\
\hline
\end{tabular}

The winding and the primary core final result of the linear motor designed are depicted in Figure 4.

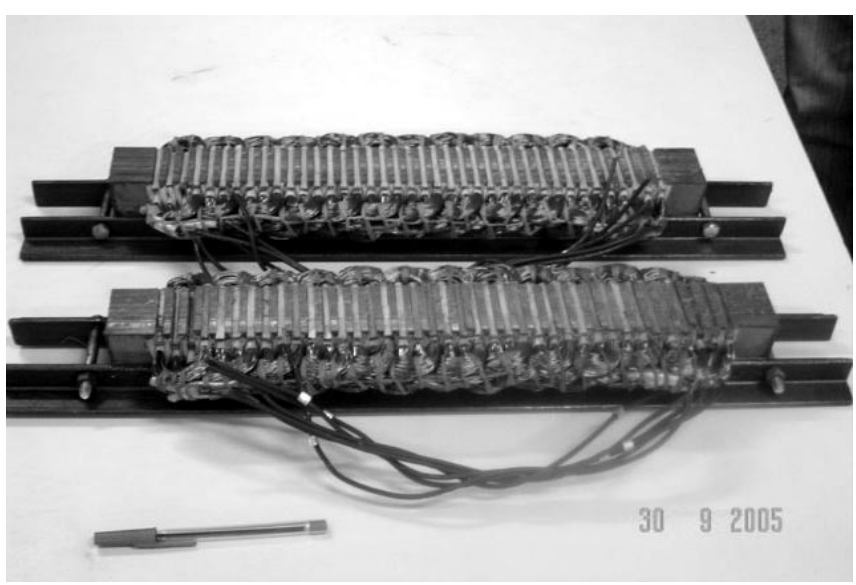

Fig. 4. Linear motor designed.

The secondary core was assembled with aluminum sheets with $3000 \times 5.6 \times 12 \mathrm{~mm}$, due to the good magnetic current conductivity and the poor magnetic conductivity.

The width of the aluminum secondary core is assumed as the same as the width of the primary core. The aluminum secondary sheet of a LIM is equivalent with the cage rotor of a rotary motor [2]. 


\section{MECHANICAL STRUCTURE}

For the mechanical structure development, the linear motor was thought as a counterweight due to its mass characteristics and at the same time produces the traction force.

As shown in Figure 5, it is possible for both primary cores to precisely adjust the gap through the screws.

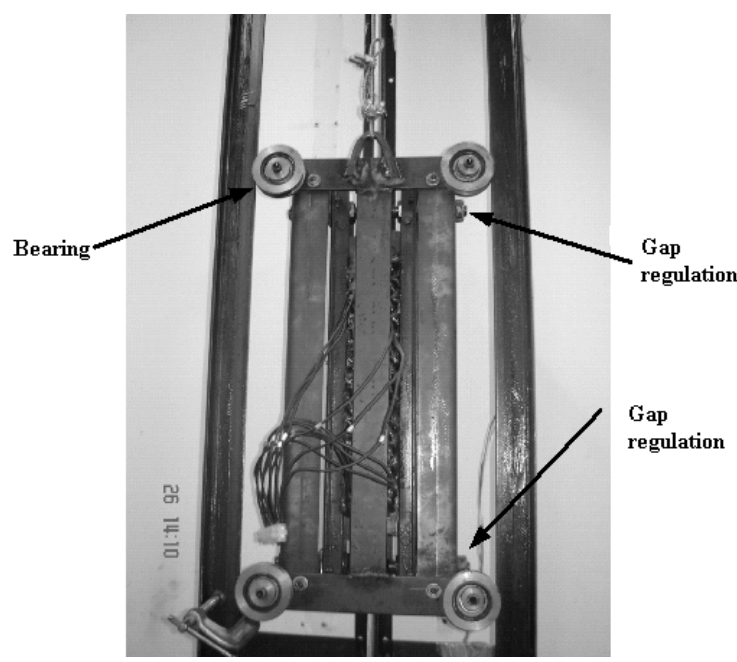

Fig. 5. Primary core structure.

Figure 6 shows the assembled mechanical structure. All the structure is shaped by $\mathrm{T}$ section angles and square tube sections of 1020 steel and $1 / 4$ inch. The mechanical structure is open without walls, easily allowing small adjustments if necessary.

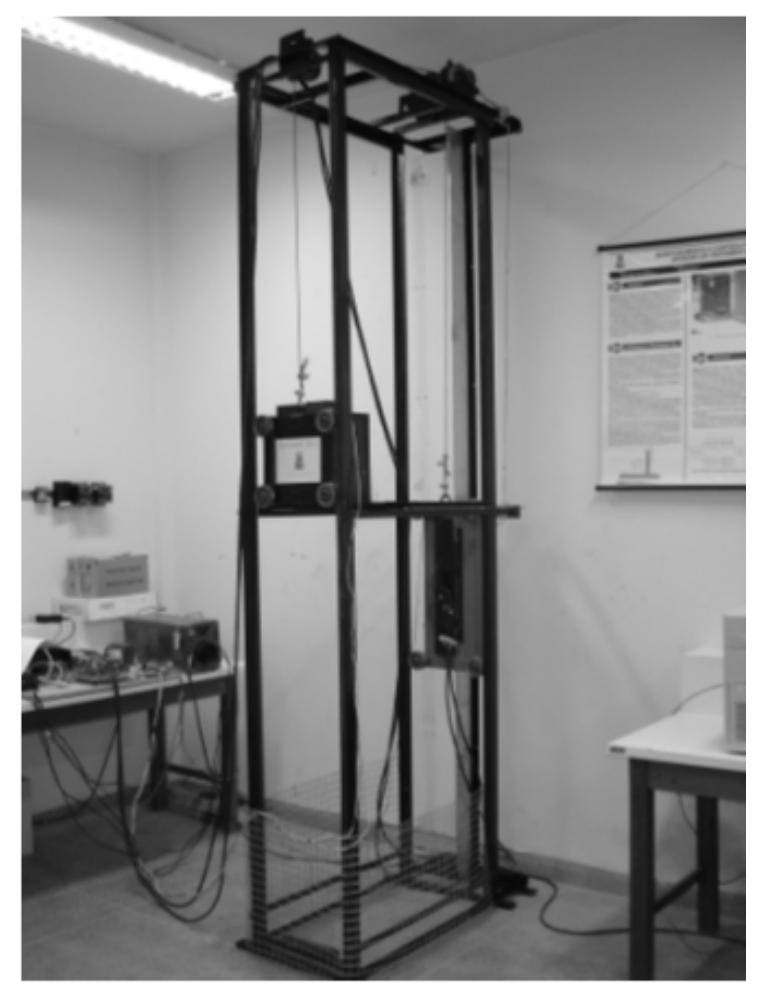

Fig. 6. Elevator structure designed.

\section{DOUBLE THREE-PHASE BRIDGE VOLTAGE SOURCE INVERTER DRIVE}

For this project, it was decided to design an inverter that fulfills the condition to supply the motor with unbalanced currents in each winding. It was considered that this experimental setup in the future will be used to fulfill several essays, as driving the LIM with unbalanced currents (each phase with a different angular displacement). These essays are requested for future works in this laboratory. Therefore the inverter that fulfills the imposed conditions is the doublebridge inverter as shown in Figure 7.

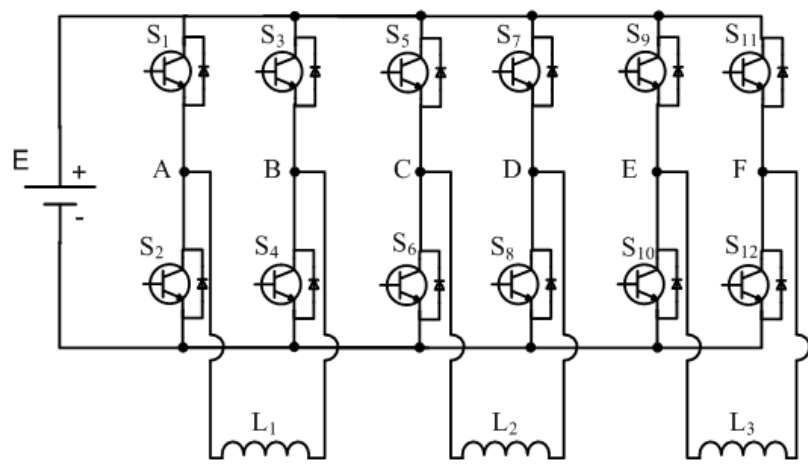

Fig. 7. Double three-phase bridge basic circuit.

Note that this type of inverter is essentially three singlephase bridges. To avoid the short circuit the three-phase load must either be separated into three electrically isolated single phase loads (see Figure 7) or a transformer must be used to provide electrical isolation [15].

The pulse width modulation (PWM) strategy used is known as unipolar modulation [16], where one phase leg is modulated in the first half of output voltage period, while the other phase leg is modulated in the second half of output voltage period, as shown in Figure 8.

In this strategy on the first half cycle, the IGBTs $\mathrm{S} 1$ and S4 are modulated, while the IGBTS S2 and S3 are turned off. After, on the second half cycle, the sequence is inverted (S1 and $\mathrm{S} 2$ are turned off; $\mathrm{S} 2$ and $\mathrm{S} 3$ are modulated).

It was used as reference a digital rectified sinewave waveform (Vsin) and a digital triangular waveform (Vtri) as carrier, as shown in Figure 8

The double bridge gives a $320 \mathrm{Vrms}$ output voltage at a $20 \mathrm{~Hz}$ rated frequency.

The inverter specifications are shown in Table 2.

TABLE II

Specifications

\begin{tabular}{cc}
\hline Output power & $5400 \mathrm{VA}$ \\
\hline Supplied voltage & $380 \mathrm{Vac}$ \\
\hline Rated output voltage & $220 \mathrm{Vac}$ \\
\hline Supplied frequency & $60 \mathrm{~Hz}$ \\
\hline Switching frequency & $7500 \mathrm{~Hz}$ \\
\hline Output voltage frequency & $20 \mathrm{~Hz}$
\end{tabular}




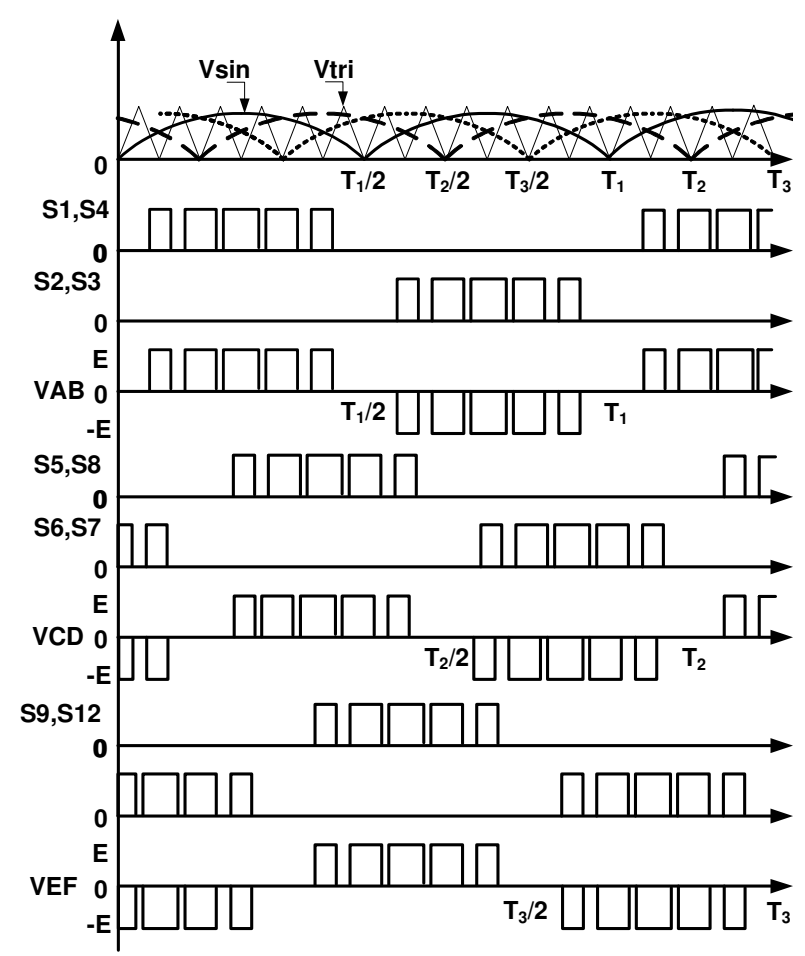

Fig. 8. PWM switching pattern for the double three-phase bridge designed.

\section{SPEED CONTROL}

The choice of the speed control strategy is very important for the determination of the key performance characteristics of the driver.

The open loop speed control of the linear induction motor operating with an adjustable frequency was used, since the elevator prototype has as requirement a soft-start and smooth break (acceleration and deceleration).

The strategy chosen to accomplish the acceleration and breaking of the elevator was the scalar v/f control technique, because it is commonly used for open loop PWM inverter (without speed feedback), as shown in Figure 9.

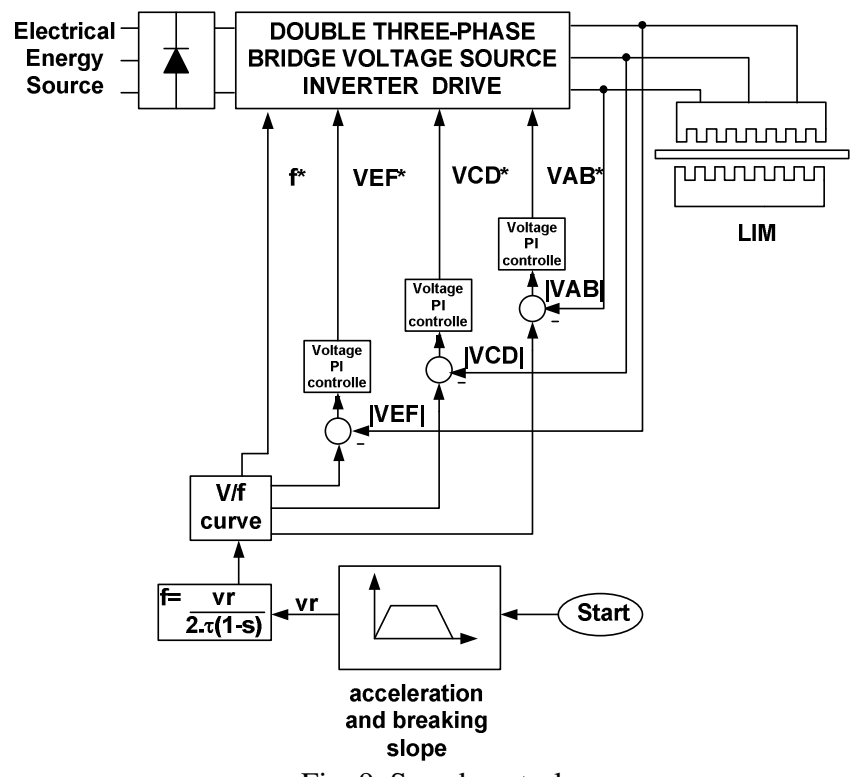

Fig. 9. Speed control
The control system was implemented using a Digital Signal Processor (DSP) TMS320F2812 Texas Instruments ${ }^{\circledR}$, which has high-speed processing, high memory capacity and a range of mathematical instructions using a numerical representation of fixed or floating point.

In order to keep the primary core flux constant, a digital $\mathrm{V} / \mathrm{f}$ curve was programmed in the DSP allowing the reduction of the speed and keeping the ratio between the voltage magnitude and the frequency constant.

\section{EXPERIMENTAL RESULTS}

It will be presented below the preliminary experimental results with the operation characteristics of the system.

Figure 10 shows the LIM current waveforms and Figure 11 shows the output voltage waveform that feeds the linear induction motor with 220 RMS voltage, $20 \mathrm{~Hz}$ output frequency and 120 degrees angular displacement.

Using the scalar v/f control technique, an algorithm in the DSP was implemented, so that the motor acceleration time is approximately $1.5 \mathrm{~s}$ and the breaking time is approximately $2,5 \mathrm{~s}$.

Using the scalar v/f control technique, an algorithm in the DSP was implemented, so that the motor acceleration time is approximately $1.5 \mathrm{~s}$ and the breaking time is approximately $2,5 \mathrm{~s}$.

Figure 12 and Figure 13 show the current waveforms of the designed LIM, for acceleration and breaking. The LIM was supplied with a voltage variation from 0 to $220 \mathrm{~V}$ (see Figure 12) and from 220 to $0 \mathrm{~V}$ (see Figure 13). The supplied electrical frequency also changes from 0 to $20 \mathrm{~Hz}$ (see Figure 12) and from 20 to $0 \mathrm{~Hz}$ (see Figure 13). The feeding voltage in these pictures has 120 degree of angular displacement.

The result of this elevator prototype can also be watched on [17].

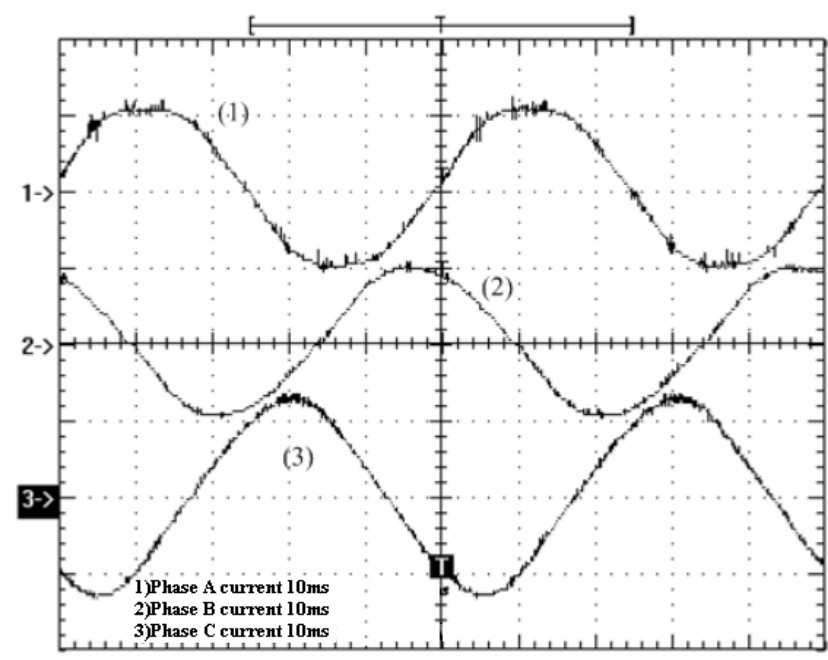

Fig. 10. Motor current waveform 1)=2)=3)10A/div; $10 \mathrm{~ms} /$ div. 


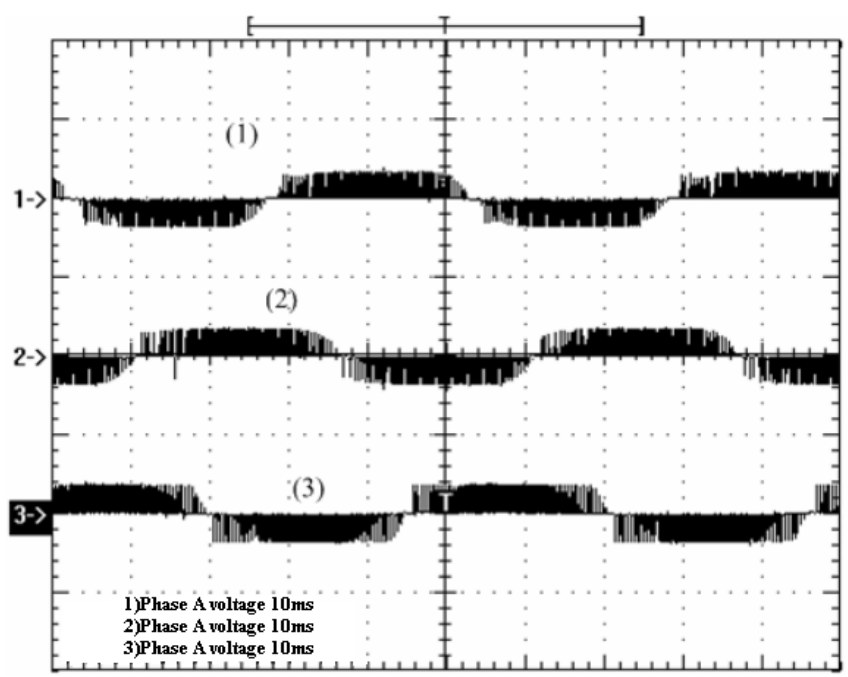

Fig. 11. Output voltage waveform 1)=2)=3) $1 \mathrm{kV} / \mathrm{div} ; 10 \mathrm{~ms} / \mathrm{div}$.

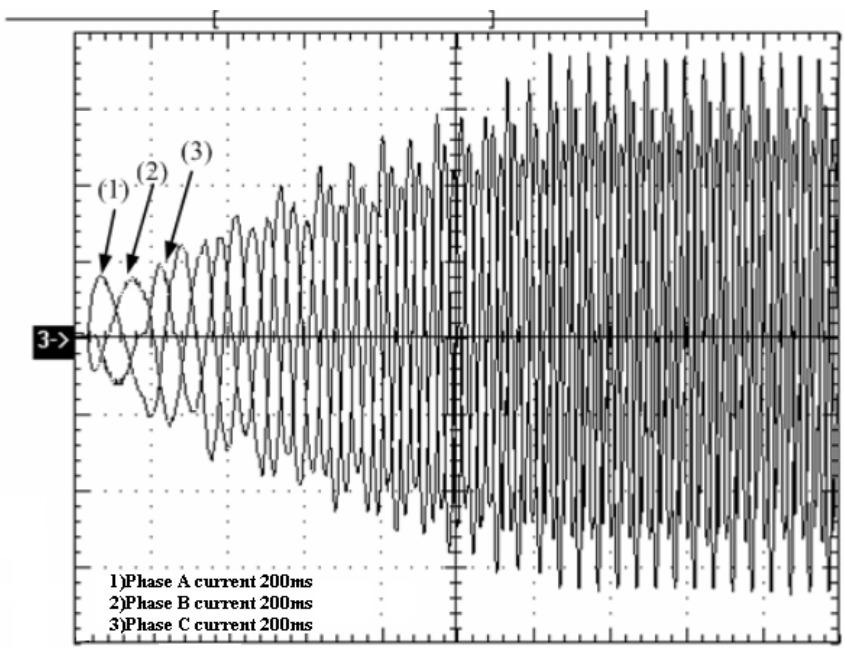

Fig. 12. LIM current waveform for a soft-start. 1)=2)=3)5A/div; $200 \mathrm{~ms} / \mathrm{div}$.

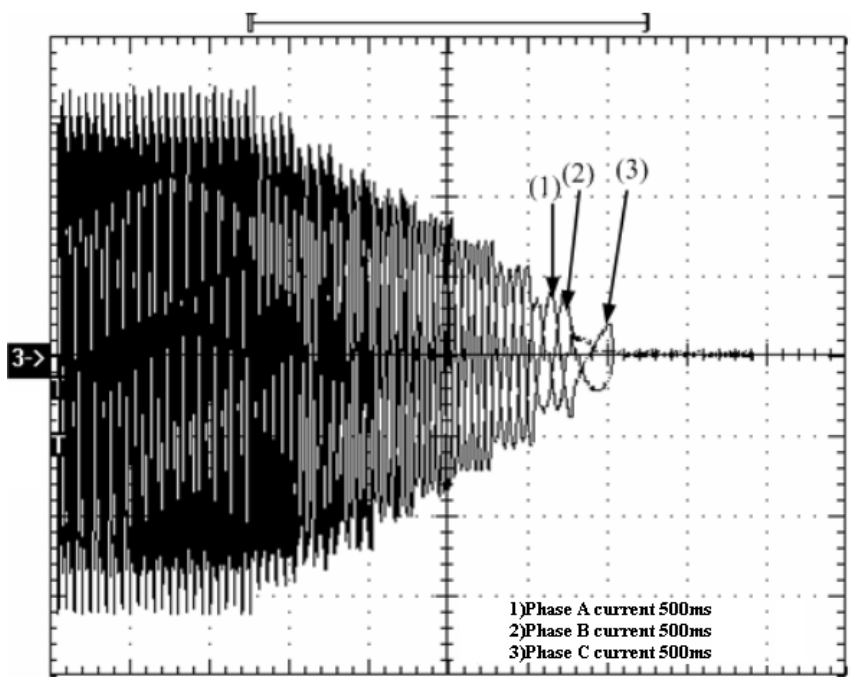

Fig. 13. LIM current waveform for breaking. 1)=2)=3)5A/div; $200 \mathrm{~ms} / \mathrm{div}$.

\section{CONCLUSION}

In this work was presented the theoretical and experimental study of a counterweight elevator using a linear induction motor. An elevator prototype using a LIM was built and experimentally tested, consisting of the mechanical structure of the elevator, the electromagnetic break system, the drive and the control unit.

As the double-bridge inverter is equivalent to three fullbridge inverters, the DSP can control independently each one of them, that is, to impose output voltage levels, angular displacement and output frequency separately. Therefore, the use of this inverter becomes an important tool to impose different feeding conditions (unbalanced currents) for future analysis, as the determination of LIM parameters from the equivalence between LIM and the ordinary asymmetrical rotary induction motor [18]. Other methods for position and speed control can also be implemented in the future, increasing a linear position sensor (optical, laser based, inductive, capacitive etc) in the path or a rotary encoder in the pulley.

With the use of this technology, a paradigm break may occur due to a new elevator construction method, not existing in the standards.

Therefore, using the linear motor to drive an elevator, the passenger may have better ride quality and comfort in the ascent and descent, due to the speed control [4].

It provides also easier maintenance and inspection access due to the motor topology.

Besides, no penthouse machine room is required. Thus, considerable building space can be saved and more space can be profitable rented [10].

Load optimizations, high speed, no gear-reductions, saving energy are others important advantages.

The application of this technology aims at warehouses, ports, industrial and commercial elevators.

\section{ACKNOWLEDGEMENT}

The authors would like to thank FUNCAP and CNPq for the financial support and Texas Instruments for providing the DSP platform.

\section{REFERENCES}

[1] E. R. Laithwaite, "Linear electric machines - a personal view", in Proc. of the IEEE, v. 63, no. 2, pp. 250-290, February 1975.

[2] J. F. Gieras, Linear Induction Drives, Clarendon Press Oxford, London, UK. pp. 298, 1994.

[3] A. Cassat, N. Corsi, R. Moser, N. Wavre, "Direct Linear Drives: market and performances status", in Proc. of Linear Drives for Industrial Applications - LDIA, Austin Court, Birmingham UK, pp.1-11, 2003.

[4] J. F. Gieras s, J.F. and Z. J. Piech, Linear Synchronous Motors, CRC Press LLC, Washington, D.C, 1999.

[5] R. Krishnan, H. S. Lim and N. S. Lobo, "Comparison of Linear Switched Reluctance Machines for Vertical Propulsion Application: Analysis, Design, and Experimental Correlation" , IEEE Transactions on 
Industry Applications, v. 44., no. 4, pp. 1134-1142, July/August 2008.

[6] J.F. Gieras, P.D. Hartzenberg, I.J. Magura and M. Wing, "Control of an elevator drive with a single-sided linear motor". The European Power Electronics Association, pp. 353-358, 1993.

[7] T. R. Fernandes Neto, R. S. T. Pontes, "Design of a vertical conveying system using a three-phase doublesided linear induction motor", in Proc. of $7^{\text {th }}$ IEEE International Conference On Industrial Applications INDUSCON, Recife, CDROM, 2006.

[8] S. Torri,N. Izuno,M. Watada, and D. Ebihara, "Optimum control scheme for the maximum efficiency drive of linear synchronous motor used for ropeless elevator", Electrical Engineering in Japan, Vol. 155, No. 3, May 2006, pp. 70-78.

[9] T. Morizane and E. Masada, "Study on the feasibility of application of linear induction motor for vertical movement," IEEE Transactions on Magnetics, vol. 29, no. 6, pp. 2938-2940, Nov. 1993.

[10] T. Ishii, "Elevators for skyscrapers", IEEE Spectrum, pp. 42-46, 1994.

[11]H. Jappsen, "High Rise Elevators for the 21th century", in Proc. of Elevcon 2002, Milano, June 2002.

[12] S.A Nasar and I. Boldea, The Induction Machine Handbook, CRC Press 2001.

[13]G. H. Abdou and S. A. Sherif, "Theoretical and Experimental design of LIM in automated Manufacturing System", IEEE Transactions on Industry Applications, v. 27., no. 2, pp. 289-293, March/April 1991.

[14]R. Richter, Elektrische Maschinen - Band 4., Verlag Birkhäuser, Bassel und Stuttgart, 1954
[15]T. A. Lipo and D. G. Holmes, Pulse width modulation for power converters: Principles and practice, WileyIEEE press, pp. 744, 2003.

[16] M. H. Rashid, Power Electronics: Circuits, Devices and Applications, Pretince Hall, 3 edition, pp. 912, 2003.

[17]T. R. Fernandes Neto, "Elevador utilizando motor linear", April 2008; http://www.youtube.com/watch?v=HK9cAvwO7kQ

[18]R. S. T. Pontes, Modelagem do motor de indução linear baseando-se na equivalência com motor rotativo, Doctorate Thesis, Federal University of Uberlândia, 2003.

\section{BIOGRAPHIES}

Tobias Rafael Fernandes Neto was born in FortalezaCE, Brazil, in 1981. He received the bachelor degree in electrical engineering from Fortaleza University, Fortaleza, in 2004 and the master degree (M.Sc) in electrical engineering from Ceará Federal University, Fortaleza, in 2007. At this moment, is doing his Ph.D thesis in the Laboratory of Power Electronics and Control Drives, Darmstadt University of Technology, Darmstadt, Germany, on "Research of a short primary linear drive with contactless energy transmission".

Ricardo Silva Thé Pontes was born in Fortaleza-CE, Brazil, in 1956. He received the bachelor degree in electrical engineering from Ceará Federal University, Fortaleza, in 1979, the master degree (M.Sc) in electrical engineering from Brasilia University, Brasilia, in 1983 and the Ph.D degree in electrical engineering from Uberlandia Federal University, Uberlandia, in 2003. Since 1979, he has been Professor of the Ceará Federal University. His research activities include ac drives, linear electric machines and industrial energy efficiency. 